\title{
Abandono e acolhimento institucional: Estudo de caso sobre maioridade e desinstitucionalização
}

\author{
Abandonment and institutional sheltering: Case study on majority and deinstitutionalization
}

Martha Emanuela Soares da Silva Figueiróo[a], Herculano Ricardo Campos ${ }^{[b]}$

\footnotetext{
[a] Psicóloga, mestre em Psicologia pela Universidade Federal do Rio Grande do Norte (UFRGN), docente do curso de Psicologia da Universidade Potiguar (UnB), Natal, RN - Brasil, e-mail: marthaess@gmail.com

[b] Psicólogo, doutor em Educação pela Universidade Federal do Rio Grande do Norte (UFRN), professor do Departamento e do Programa de Pós-Graduação em Psicologia da Universidade Federal do Rio Grande do Norte (UFRN), Natal, RN - Brasil, e-mail: hercules@ufrnet.br
}

Recebido: 08/05/2011 Received: 05/08/2011

Aprovado: 20/09/2011 Approved: 09/20/2011

\section{Resumo}

0 presente estudo buscou identificar o papel da rede de acolhimento institucional no que diz respeito à preparação e à orientação do jovem para a vida pós-desligamento obrigatório devido à maioridade. Realizou-se um estudo de caso da trajetória institucional de um jovem com mais de 18 anos de idade, institucionalizado em abrigo municipal para adolescentes desde os 15 anos, impossibilitado de retornar à família e à comunidade de origem, e recém-egresso. A escolha do sujeito de referência para o estudo ocorreu por meio de entrevistas exploratórias realizadas com funcionários da Rede de Apoio à Criança e ao Adolescente em Situação de Risco na cidade de Natal (RN). As informações sobre o caso foram colhidas por meio de entrevistas abertas com o jovem, os educadores e os gestores da rede em Natal, visitas exploratórias a ambientes e locais de referência da vida do jovem, leitura de documentações referentes à vida institucional do jovem e notas de campo. A análise dos dados apontou o despreparo e a pouca habilidade do jovem no trato com a vida social de um mundo adulto, bem como uma incompatibilidade entre os seus planos e desejos relacionados à sua vida pós-abrigo e as opções oferecidas pela rede de acolhimento. Tal situação decorre da falta de um projeto político-pedagógico da instituição de acolhimento e de políticas públicas voltadas para essa questão. Esses elementos indicam que o acolhimento institucional contribui para uma inclusão precária, podendo acarretar uma série de novas situações de risco à vida do sujeito.

Palavras-chave: Jovem. Estudo de caso. Políticas públicas. Acolhimento institucional. Desligamento obrigatório.

\section{Abstract}

The present study aimed at identifying the role of the institutional sheltering net in what concerns to the preparation and orientation of the youth to the life after the obligatory unbound due to majority. It was realized a case study of a young person institutional trajectory, over 18 years old, institutionalized in a municipal shelter to teenagers since 15 , unable to return to his family and his original community, and recent egress. The choice of the reference subject to the study happened by the exploratory interviews realized with employees of the child and teenager in danger situation support net from the city of Natal (RN). The information about the case were collected by open interviews with the young person, the educators and the net managers in Natal, exploratory visits to environments and places of reference of the youth life, documentation reading referring to 
institutional life of the young person and field notes. The data analysis indicated the unpreparedness, the little ability of the young on the treat with the adult world social life, as well as an incompatibility between his plans and wishes related to his social life after shelter, and the options offered by the sheltering net. This situation happens because of the lack of a political-pedagogical project of the sheltering institution and the public politics faced to this question. These elements indicate that the institutional sheltering contributes to a precarious inclusion which may result in a series of new dangerous situations to the life of the subject.

Keywords: Youth. Case study. Public politics. Institutional sheltering. Obligatory unbound.

\section{Introdução}

0 acolhimento institucional é uma medida de proteção prevista no artigo 101 do Estatuto da Criança e do Adolescente (ECA), direcionada a indivíduos de zero a 18 anos de idade em situação de abandono ou cujas famílias encontram-se temporariamente impossibilitadas de prover-lhes os cuidados necessários. O ECA busca garantir o devido suporte emocional e social aos que vivem tal experiência. Os serviços de acolhimento para crianças e adolescentes devem se pautar em diversos documentos ${ }^{1}$, todos eles fruto de intensa discussão com a sociedade civil, principalmente no contexto da promulgação da Constituição de 1988.

Visando à melhoria das condições de garantia de direitos às pessoas que passam por tal experiência, em 2008, o Conselho Nacional da Criança e do Adolescente (Conanda) e o Conselho Nacional de Assistência Social (CNAS) publicaram um documento intitulado Orientações técnicas para os serviços de acolhimento para crianças e adolescentes. Esse documento reúne princípios, orientações metodológicas e parâmetros de funcionamento para diversas modalidades de acolhimento, como o abrigo institucional - seja ele de natureza público-estadual ou não. No documento, consta que os serviços de acolhimento devem ter os seguintes princípios: a) a excepcionalidade e a provisoriedade do afastamento do convívio familiar;

b) a preservação e o fortalecimento dos vínculos familiares e comunitários;

c) a garantia de acesso e respeito à diversidade e não discriminação;

d) a oferta de atendimento personalizado e individualizado;

e) a garantia de liberdade de crença e religião;

f) e o respeito à autonomia da criança, do adolescente e do jovem.

Como o público alvo dos abrigos deve ter no máximo 18 anos, para aqueles que não tiveram seus vínculos familiares e comunitários restabelecidos ou não foram encaminhados à família substituta, o desabrigamento é necessário com a maioridade. As orientações metodológicas para o desligamento - motivado pela maioridade ou não - constantes do documento (Conanda \& CNAS, 2008), apontam na perspectiva de um processo gradativo. No caso dos adolescentes, o serviço deve incluir o acesso a programas de qualificação profissional e inserção no mercado de trabalho. É ressaltada a importância de manter parcerias com programas de repúblicas ${ }^{2}$, que podem ser muito importantes no processo de transição entre o abrigo e a vida autônoma e independente nos caso de desligamento devido à maioridade.

\footnotetext{
1 Estatuto da Criança e do Adolescente, Plano Nacional de Promoção, Proteção e Defesa do Direito de Crianças e Adolescentes à Convivência Familiar e Comunitária, Política Nacional de Assistência Social e Projeto de Diretrizes das Nações Unidas sobre Emprego e Condições Adequadas de Cuidados Alternativos com crianças.

2 Repúblicas se apresentam como uma opção para o desligamento gradativo de jovens em processo de desinstitucionalização. Essas oferecem apoio e moradia subsidiada para adolescentes durante o período de desligamento. 0 objetivo dessa modalidade de acolhimento é trabalhar a independência, a autogestão e a autonomia do jovem que agora deve estar fora da instituição. Elas devem se localizar numa área residencial, não muito diferente do local onde se situava o serviço de acolhimento no qual o jovem estava inserido e também não muito distinta da sua comunidade de origem (Conanda \& CNAS, 2008).
} 
Portanto, é esperado que as instituições de acolhimento preparem o jovem para esse momento de desligamento, contemplando o fortalecimento da autonomia, a profissionalização, a educação, estabelecendo um processo de desligamento gradativo. A orientação é para que tais ações façam parte do projeto político-pedagógico dos serviços de acolhimento institucional, de modo a oferecer a segurança necessária para aquele que não mais terá o suporte do Estatuto, passados os 18 anos.

Mas o que é o desligamento, quais implicações sobre o sujeito? No âmbito emocional e afetivo, o momento de transição, representado pela preparação para o desligamento, pode se apresentar como uma situação de conflito entre estar na instituição e sair para a sociedade. Tomando por base a reflexão de Constantino (2000), ao ser desligado da instituição, o jovem pode se sentir perdido por fazer parte de "dois mundos" e de nenhum deles, ao mesmo tempo.

No caso daqueles com longos períodos de institucionalização e vínculos familiares e comunitários fragilizados, a grande rotatividade de outros adolescentes (Janczura, 2005), ou mesmo de funcionários, e a frágil vinculação do abrigo com a comunidade onde está localizado ${ }^{3}$ constituem dificuldades à vinculação afetiva durante o período de acolhimento e prejuízo ao seu desenvolvimento emocional e afetivo. Como apontam Siqueira e Dell'Aglio (2006, p. 71), "os efeitos de um período de institucionalização prolongado têm sido apontados na literatura, por interferirem na sociabilidade e na manutenção de vínculos afetivos na vida adulta".

Sob esse prisma, o período de transição com vistas à saída do abrigo é também acompanhado por mais um fator gerador de insegurança, qual seja a passagem para a vida adulta. Ela representa um novo status legal, bem como um desafio econômico, afetivo e social, em face do que afloram sentimentos de angústia, medo, abandono (renovação do abandono), ou mesmo revolta. Figueiredo, Sader, e Caldeira (1987) apontam que, em instituições onde meninos vivem privados de socialização, é comum que entrem em crise ao se aproximarem da maioridade e, consequentemente, da saída obrigatória da instituição. Sem preparo e apoio, egressos de serviços de acolhimento institucional podem seguir caminhos que os submetam a situações de risco como a rua, o tráfico e as prisões. No entender de Constantino (2000, p. 29),

ao interiorizar uma imagem negativa de si mesmo, adquirida a partir da visão que a instituição tem dele e que é reforçada pela sociedade, o adolescente percorre um caminho que pode levá-lo ao crime e à violência. Ao sentir-se excluído da instituição, que não o quer mais por ele já ter completado 18 anos, e pela sociedade que, ao vê-lo como marginal, não o aceita, ele fica sem alternativas, restando-lhe a delinquência e a marginalidade.

Assim, caracterizada a problemática, algumas questões aqui se colocam: como atuam os serviços de acolhimento institucional ${ }^{4}$ no processo de desligamento obrigatório de adolescentes por maioridade? Mais especificamente, como a rede de acolhimento institucional de Natal (RN) trabalha o processo de desinstitucionalização, que ações são efetivadas, que efeitos possuem?

\section{Procedimentos do estudo}

Na intenção de lançar luzes sobre tais questões, desenvolveu-se um estudo do caso de um jovem, aqui chamado José. Na oportunidade da pesquisa ele se encontrava com 18 anos completos, com histórico de abrigamento institucional desde os 14 anos, e estava recém-egresso de um abrigo público

3 Em um levantamento realizado pelo Instituto de Pesquisa Econômica Aplicada (Ipea), em parceria com o Conanda (2004), foi constatado que, dos 589 abrigos da Rede de Serviço de Ação Continuada (SAC), apenas 6,6\% deles promoviam a participação de crianças e adolescentes abrigados na vida da comunidade local.

4 Os abrigos ligados ao município de Natal (RN) são chamados de Casas de Passagem, voltadas para o atendimento emergencial de crianças ou adolescentes que, por algum motivo, tiveram de ser afastados do convívio familiar e comunitário. A Casa de Passagem I tem por objetivo atender crianças de 0 a 6 anos; a Casa de Passagem II atende aquelas com idade entre 7 e 11 anos; e a Casa de Passagem III atende adolescentes, dos 12 aos 18 anos.

Psicol. Argum. 2013 jan./mar., $31(72), 113-125$ 
da cidade do Natal (RN). Foram feitas entrevistas abertas gravadas em áudio com vários agentes: o adolescente participante da pesquisa; os educadores do abrigo onde se encontrava (a coordenadora, a assistente social, o arte-educador e o pedagogo da Casa de Passagem III ${ }^{5}$ ); e os gestores da rede de atendimento da cidade e do estado (a coordenadora do Serviço Social das Casas de Passagem em Natal; a coordenadora do programa estadual SOS Criança ${ }^{6}$, a quem José recorreu certa vez, pedindo para ser abrigado; e a coordenadora do $\mathrm{PETI}^{7}$, onde ele trabalhou após sua desinstitucionalização).

Compôs-se também um diário de campo, com registros das visitas a alguns locais de referência do adolescente: a Casa de Passagem III, instituição de abrigo destinada a atender adolescentes do gênero masculino e feminino na faixa etária entre 12 e 18 anos de idade, onde José permaneceu institucionalizado por cerca de quatro anos; o SOS Criança, instituição em que o jovem buscou ajuda e apoio em alguns momentos da sua trajetória institucional; o PETI, que foi o local de trabalho dele após sua desinstitucionalização; e a residência em que passou a viver após seu desligamento do abrigo.

Com o adolescente foram realizadas sete entrevistas abertas, previamente agendadas, visando o fortalecimento do vínculo entre ele e a pesquisadora, bem como ao detalhamento de informações. Outros encontros não programados ocorreram, como quando se visitou a Casa de Passagem III e se conversou a respeito do seu cotidiano no abrigo, suas angústias com relação à saída e seus planos para o futuro. Nesse caso, os registros foram realizados em notas no diário de campo. Também se analisou a documentação referente à sua trajetória institucional, com o objetivo de reconstituí-la, desde seu primeiro acolhimento até a fase pós-abrigo. Identificaram-se as datas dos abrigamentos e desabrigamentos, dados da família e da comunidade de origem, e ações promovidas pela rede durante o período de institucionalização.

Por se tratar de um estudo de caso, a coleta de informações levou um tempo consideravelmente longo, que durou de outubro de 2009 a abril de 2010. Foram seis meses em contato com informações e situações que subsidiaram a reconstituição da trajetória institucional de José e o conhecimento de importantes aspectos da sua vida no abrigo. Foi possível também acompanhar os últimos momentos de José no abrigo e o começo da sua trajetória fora dele.

\section{0 caso em questão}

Como já referido, José é o nome fictício de um jovem nascido em 11 de outubro de 1990, em Natal (RN). Ele foi, por diversas vezes, abrigado desde os

\footnotetext{
5 A Casa de Passagem III situa-se em um bairro de classe média e alta da cidade e abriga em torno de 20 meninos e meninas, registrando alta rotatividade. A estrutura física do imóvel atende ao preconizado no ECA (1990), com quatro dormitórios coletivos, banheiros masculino e feminino, sala, cozinha, espaço para refeições, lavanderia e área externa de lazer. Possui piscina e quadra poliesportiva, que os adolescentes usufruem em horários recreativos.

Apesar dos dormitórios serem equipados com armários e camas, nem o número de leitos - dez - e nem o de adolescentes por dormitório - observou-se até 12 - está de acordo com o recomendado nas Orientações Técnicas para Serviços de Acolhimento Institucional para Crianças e Adolescentes (2008), de no máximo seis pessoas. A coordenadora relatou, em entrevista, que a instituição chegou a atender mais de 40 adolescentes de uma só vez, no último ano.

A equipe da Casa é composta por 24 educadores, um pedagogo, dois auxiliares de serviços gerais, um arte-educador, dois auxiliares de enfermagem, dois assistentes sociais, um psicólogo e uma coordenadora, também assistente social.

${ }^{6}$ O SOS Criança é um programa do governo do estado do Rio Grande do Norte criado em 1992, no contexto do Pacto pela Infância. Tem por objetivo receber denúncias relacionadas à violação de direitos de crianças e adolescentes e encaminhar as vítimas para os serviços de atendimento adequados. É um programa de referência para a população do estado - notadamente da capital, onde está localizado - e para crianças e adolescentes, muitos dos quais procuram espontaneamente pelo serviço. Funciona 24 horas por dia, inclusive nos finais de semana e feriados.

7 No processo de desligamento ocorreram algumas tentativas de inserir José no mercado de trabalho, por meio de cursos e estágios em diversos ofícios. Já na iminência de sua saída ele passou a exercer o cargo de Auxiliar de Serviços Gerais (ASG) em um dos PETI da capital. Esse programa do Governo Federal destina-se a retirar do trabalho crianças com até 14 anos, oferecendo serviços de restabelecimento de vínculos sociais e comunitários e oferecendo auxílio financeiro para as famílias, por meio da integração com o Programa Bolsa Família.

Por esse ofício, José passou a receber a quantia mensal de um salário mínimo, bem como auxílio-transporte e alimentação.
} 
14 anos, e a partir do mês de julho de 2006 foi abrigado e somente se desligou da instituição depois de atingida a maioridade.

Ele conta que viveu os primeiros anos da sua vida junto com sua mãe e seu pai no bairro do Igapó, na zona norte da cidade. A mãe efetuava os serviços domésticos, enquanto o pai provia o sustento da família, trabalhando como policial civil. José afirma ter poucas lembranças do pai, de quem a mãe se separou quando ele era muito pequeno, mas se sente triste com saída dele de casa para não mais retornar, e tampouco dar notícias. Relatou ter saudades da vida que levava nessa época; assegurou que nunca sofrera agressão física do seu pai; disse que gostava muito de brincar com os amigos da mesma rua e de ir à casa de uma vizinha, amiga da sua mãe, que tinha um filho da mesma idade que ele.

Com 10 anos de idade sofreu uma queimadura muito grave que, além da cicatriz que cobre boa parte do corpo (das pernas ao pescoço), lhe rendeu o apelido de "O queimado". Ao relatar o acidente, mostrou-se comovido, afirmando ter sofrido muito no tempo em que passou hospitalizado, mas que sua mãe lhe deu suporte durante o período de recuperação.

Essa queimadura foi antes de eu vir pra cá [para o abrigo onde se encontrava por ocasião da entrevista] ... foi no São João, e eu tinha 10 anos. Estava sentado no meio-fio, assando milho na fogueira, aío irmão do meu colega lá de longe rebolou um álcool na fogueira. Aí quando caiu na fogueira, explodiu e caiu todo em cima de mim. Passei um mês e alguns dias no hospital. Fiquei sem conseguir andar. Fiz duas cirurgias nas pernas. Com o tempo, consegui andar... mas no começo só andava agachado, porque não conseguia esticar as pernas, nem mexer os $\operatorname{braços}^{8}$ (15 de outubro de 2009).

Para ele, após separar-se do seu pai, o comportamento da sua mãe foi se transformando; ela passou a ser agressiva, sempre muito irritada, e a não demonstrar nenhuma paciência com ele. Ainda que desejasse permanecer dentro de casa, ela pedia para que ele ficasse brincando fora o dia inteiro, razão por que ficava tanto tempo na casa da vizinha.
Afirmou que, para prover o sustento da família depois da separação, sua mãe passou a oferecer serviços de faxineira, pelos quais recebia muito pouco, embora não tenha sabido especificar a quantia.

Alguns anos depois, com novo companheiro, sua mãe teve o segundo filho; e mais tarde, casou-se e passou a viver com outro homem. Com o novo marido sua mãe teve mais um filho; nessa época José tinha 11 anos de idade. Assim, a família era composta por José, seus dois irmãos mais novos, sua mãe e seu padrasto. Muito embora a nova sogra da sua mãe, sabendo das condições precárias em que a família vivia, ajudasse mensalmente com algum dinheiro, o padrasto tornou-se um grande entrave para a permanência de José no ambiente familiar.

Foi relatado por José, e também consta nos relatórios de visitas psicossociais da Casa de Passagem III, que o seu padrasto era alcoolista e fazia uso abusivo de drogas, como o crack; não possuía emprego fixo, fazendo bicos ocasionais; era bastante violento, chegando a agredir fisicamente sua mãe, ele e seus irmãos, com bastante frequência. A vida na sua casa tornou-se insuportável depois do novo casamento da mãe.

Antes de ele ir morar lá, mãe era boa demais. Depois que esse rapaz foi morar lá, ficou tudo de cabeça pra baixo. Mãe não dava mais atenção pra gente; a gente chegava dentro de casa, ela mandava a gente sair de dentro de casa. A gente queria entrar pra tomar água, aí ela dizia: "eu disse o quê? Não era pra entrar!". Aí a gente saía (15 de outubro de 2009).

Na visão de José, os comportamentos agressivos de seu padrasto alteravam ainda mais o comportamento da sua mãe, que passou a tratá-lo com bastante intolerância. A maior parte das brigas e discussões em casa ocorria pelo fato de seu padrasto querer dinheiro, pedindo-o constantemente à sua mãe.

Uma vez, fui pedir dinheiro a ela. Pedia assim... dez reais, que lá, antigamente, tinha a Feira da Sulanca, sabe? Aí tinha lá camisa, bermuda de cinco reais, sabe? Aí dizia "mãe, me dê dez reais". Aí, ela "não tem não!". Eu, "tá certo". Aí meu padrasto vai lá e

8 Os funcionários do abrigo acreditam que a queimadura tenha sido resultado de algum tipo de negligência familiar. Contudo, não dispondo de depoimento de outra testemunha do evento, considera-se, para efeito deste estudo, a versão de José.

Psicol. Argum. 2013 jan./mar., 31 (72), 113-125 
pede 30 reais a ela; ela pega e dá na hora. Ele gasta tudo num instante... torra tudo de droga! (15 de outubro de 2009).

Por não concordar com a situação existente em sua casa, José passou a ter atritos constantes com seu padrasto, criando uma relação de forte inimizade. Afirmou que na maior parte das vezes seu padrasto tratava sua mãe com indiferença, quando não era bastante agressivo. Ao se referir a essa situação durante as entrevistas, o jovem sempre se mostrava bastante inconformado, afirmando que não entendia como sua mãe se submetia a tantos maus-tratos - além de ver seus filhos sendo também maltratados - e nada fazia para mudar a situação.

Aos 14 anos de idade, no dia $1^{\circ}$ de setembro de 2005, um mês antes do aniversário de 15 anos, José foi abrigado pela primeira vez, acusado de abusar sexualmente de duas crianças na comunidade onde vivia. Alegando inocência, explicava que apenas estava sentado em uma calçada de onde era possível ouvir gritos vindos de uma casa abandonada, próxima de onde se encontrava.

Aí pegaram os meninos. Aí, quando um deles voltou, voltou com o negócio de trás todo cheio de sangue. Aí vinha dois meninos dentro do mato lá onde ele tava, aí saíram correndo e disseram que tinha sido eu. Pra mim, isso foi a pior coisa que aconteceu... vou pagar as coisas que não fiz?! Até a mãe de um dos meninos disse que não tinha sido eu. Ela disse pra minha mãe, que ela tava muito nervosa, né? "Se acalme... não foi seu filho, não". Só que ninguém deu queixa. A assistente social daqui [do abrigo] bateu as delegacias de Natal tudinho... E ninguém deu queixa. Mas, aí, todo mundo acha que fui eu... Tudinho, tudinho... O pessoal lá da rua toda acha que fui eu... Se tivessem dado queixa não tinha isso, né? (15 de outubro de 2009).

Não se obteve informações precisas com relação ao envolvimento de José com o crime, a não ser a ausência de acusação formal na polícia por parte da família das crianças abusadas. Contudo, a comunidade o considerou culpado e, por isso, o perseguiu com promessas de morte. Em decorrência, alegando a impossibilidade de o filho voltar para casa, sua mãe solicitou a institucionalização ao Conselho Tutelar da região. Como medida de proteção, ele foi encaminhado a um dos abrigos municipais, a Casa de Passagem III, dando início ao ciclo de entradas e saídas que somente terminaria com sua maioridade.

As alegadas ameaças, que consolidaram e renovaram a rejeição sofrida da própria família, impossibilitaram a volta de José à sua casa. Segundo a coordenadora da Casa de Passagem III, "Sua mãe já mudou de endereço duas vezes, mas, mesmo assim, não objetiva criar o seu filho, pois considera que ele pode ser, inclusive, uma ameaça concreta aos seus irmãos mais novos" (13 de outubro de 2009). A coordenadora do Serviço Social das três Casas de Passagem, em Natal, relatou que,

Segundo a mãe, ele abusou sexualmente de outras crianças. Aí, ficou a vizinhança toda em cima dela; e a mãe, ela não quis mais ficar com o filho. Até o abrigo chegou muito a tentar, sabe, essa aproximação com a mãe, mas sem sucesso, ela não quer de jeito nenhum, né! ... A coordenadora do SOS, ela comentou assim, que a mãe não queria mais vínculo com ele. Foi ele mesmo quem procurou o SOS Criança pra ser abrigado de vez (15 de outubro de 2009).

Dados coletados nos relatórios psicossociais dão conta de que a mãe de José entrou em contato com o abrigo, pela primeira vez, no dia 25 de março de 2006, portanto decorridos sete meses do abrigamento, comunicada da necessidade de desabrigamento do filho. Como ela não aceitou recebê-lo, no dia 4 de abril do mesmo ano, ele foi encaminhado pelo Conselho Tutelar para a casa de uma tia, de onde saiu para morar nas ruas. Descoberto pela equipe móvel da Casa de Passagem, foi abrigado pela segunda vez. Logo depois, já no dia $1^{\circ}$ de julho de 2006, ocorreu a segunda tentativa de desabrigamento, tendo a mãe de José novamente se recusado a recebê-lo, desta feita alegando que ele poderia gerar risco para os próprios irmãos.

De acordo com a coordenadora do Serviço Social das Casas de Passagem,

Da segunda vez que ele foi desabrigado, o Conselho [Tutelar] chegou lá no abrigo e disse que tinha que levar, que já fazia tempo que ele tava ali e o atendimento tinha que ser provisório. Aí, pegaram e levaram. Sabiam que a mãe não tava querendo ele de volta. Chegaram lá na frente da casa da mãe dele, $e$ ela disse que não ia aceitar. Que assinava, mas em casa ele não entrava. Disse, ainda, que o marido 
dela falou que se ele entrasse, um dos dois saía dali morto. O Conselho, mesmo assim, deixou lá, num terreno baldio, porque na cabeça deles tinha que desabrigar de qualquer jeito. Mas a mãe dele não queria, né, não podia deixar o menino assim! Aí, depois disso, ele ficou um tempo na rua e voltou pro abrigo (15 de outubro de 2009).

Novamente foi feita uma tentativa de desabrigamento, 28 dias depois da última desastrada e mal planejada experiência, que a exemplo das anteriores também foi malsucedida. Desta feita, a mãe recebeu o filho do Conselho Tutelar, pela manhã. Contudo, logo mais ao meio-dia, sozinho, José procurou o programa SOS Criança, informando que sua mãe o havia abandonado em frente à Câmara de Vereadores de Natal, dizendo que iria trabalhar. Percebendo que ela não voltaria, sem saber o novo endereço da mãe e sem o apoio de outro parente, ele procurou o SOS Criança, solicitando acolhimento:

Eu ia ficar no meio da rua? Se eu ficasse na rua eu ia me prejudicar... Eu não ia passar fome no meio da rua, não ia passar quatro, cinco, seis dias sem tomar banho! Nada... Eu torava logo um cano, tomava logo um banho! (15 de outubro de 2009).

A coordenadora do SOS Criança relembrou o momento em que esteve com ele, nessa situação, e afirmou que,

Ele não viu mais expectativa em canto nenhum $e$ quis parar; e, na minha concepção, o abrigo não foi o melhor lugar pra ele, é como ele disse - "agora eu vou ficar aqui, porque não tenho mais pra onde correr" (5 de novembro de 2009).

Os funcionários do abrigo consideravam José bastante isolado. A grande rotatividade entre os internos também contribuiu para que desenvolvesse poucos vínculos, mesmo com outros adolescentes, muito embora tenha passado a namorar uma adolescente também institucionalizada - há ali mais de dez meninas a partir dos 4 anos de idade. No caso dela, o motivo do acolhimento foram os abusos sexuais sofridos quando criança, cometidos por seu padrasto; ela se recusou a voltar para casa - pois sua mãe continuava casada com o mesmo homem.

o fortalecimento de vínculos na comunidade onde o abrigo estava inserido também era problemático. Durante o abrigamento, José contou três mudanças de endereço do serviço, sempre para bairros de classe média e média-alta, em tudo bem distantes das comunidades de origem da maioria dos adolescentes ali abrigados. Inclusive, a mudança para o endereço onde se encontrava por ocasião deste estudo foi por demais conturbada, tendo a população do bairro se mobilizado com um abaixo-assinado pela remoção do abrigo para outro local. Longe da preocupação com a distância entre os abrigados e suas famílias, o motivo alegado era o risco que a presença dos adolescentes provocava. José relatou que havia um acordo entre o serviço e a comunidade do bairro, para que nenhum adolescente saísse da instituição sem acompanhamento de um dos funcionários.

José permaneceu no abrigo até dezembro de 2009, quando já tinha completado 19 anos de idade. Com mais de 18 anos completos, sua situação era uma das mais delicadas, pois já deveria ter sido desligado obrigatoriamente ao alcançar a maioridade.

\section{A vida na instituição}

\section{0 fortalecimento da autonomia}

O desenvolvimento da autonomia de jovens por muito tempo abrigados e em vias de desabrigamento tem como primeiro desafio vencer a sensação de dependência que neles se instaura. Ela decorre da identificação do abrigo como único espaço voltado para prover os cuidados que eles demandam, como serviço organizado e apoio afetivo e emocional. Assim, o trabalho com vistas à autonomia deve se afastar consubstancialmente de uma relação de sujeição (Soares \& Camargo Júnior, 2002), e requer ser pensado enquanto um complexo processo psíquico, pedagógico e social. A autonomia está fortemente relacionada a hábitos da vida cotidiana do jovem dentro da instituição, à construção de pessoas mais ativas e conscientes do processo ao qual estão submetidos, e ao incentivo do senso crítico.

No entanto, o que se observou foi o funcionamento do abrigo mediante regras e normas rígidas, referentes a horários e à liberdade dentro e fora dele, como é exemplo o depoimento de José, a seguir:

Esse quarto aqui a gente não pode mais entrar ... o quarto só é aberto uma vez... Olhe, tomou banho, 
tomou café, quando terminar a limpeza do quarto ninguém não entra mais ... Só na hora do almoço, que é pra tomar um banho e voltar tudo. Aí, a gente tem que ficar pela Casa, muitas vezes a gente quer vir aqui pegar um CD pra gente botar num som, eles não deixam; eu vim aqui com a maior tranquilidade aqui pedir à tia, à coordenadora daqui: "Tia, a senhora autoriza o educador pra ele abrir o quarto pra mim pegar um CD pra mim botar ali no som?" Aí ela disse: " não, não autorizo, não autorizo". Aí eu olhei assim pra cara dela, assim, disse: "Tia, a senhora fala tanto, né, quando a gente quiser uma coisa aqui dentro do quarto é só pedir pros educador, aí agora nem os educador, nem eles autoriza, manda pedir à senhora”. Aí ela: não, não, não sei o quê, não sei o quê... (15 de outubro de 2009).

De acordo com Goffman (1961), instituições totais como os abrigos caracterizam-se por adotar horários rígidos, normas estritas, quase nenhuma liberdade para ir e vir e outras características do gênero. A adoção de tais medidas somente tem em vista o melhor funcionamento institucional, fabricando uma relação de sujeição entre elas e os usuários do serviço, em detrimento da construção da autonomia dos internos. Em vez de atuar no sentido de transformar a complexa realidade de vida de cada abrigado, é a reedição dos seus problemas que a instituição acaba por conseguir. Nesse sentido, continua José:

Eu acho assim, que a gente era pra ter mais liberdade, era pra gente ter a liberdade da gente sair: "Olhe, tal horário é pra vocês voltarem, tá certo?", "Tá". Quem não viesse no horário já perdia a confiança, porque, olhe, quando a coordenadora me libera "Olhe, volte nesse horário", eu volto nesse horário. Eu só sou liberado por causa da minha idade. Eu não podia sair de jeito maneira. Se eu... olhe, se eu fosse tirar meu dinheiro do ProJovem ou do projeto [ir ao caixa sacar dinheiro], eu antes disso eu frequentei o projeto Canteiros, eu só ia com educador, ou pessoal, ou assistente social, ou coordenadora. Fazia nada sozinho. Nem com 17 anos: muito ruim (15 de outubro de 2009).

No depoimento acima, fica evidente a questão específica da proibição de saída dos adolescentes da instituição sem a companhia de um membro da equipe técnica. Refere um acordo informal entre a direção da Casa e representantes do bairro onde ela estava situada, com base em que era proibido aos abrigados circularem sozinhos pelas redondezas. Inclusive, durante as visitas ao abrigo se observou a presença de um guarda municipal na entrada da casa, e membros da equipe deram conta da presença de policiamento durante 24 horas. 0 serviço de guarda, ao mesmo tempo em que visava à segurança do entorno, garantia a contenção dos adolescentes. Estes facilmente perdiam sua posição de vítimas para se constituírem em ameaça.

Na esteira do que afirma Lancetti (2009, p. 83), para quem a assistência social "nunca estará em condições de produzir efeitos transformadores se não criar dispositivos cogestivos e autogestionários", incentivar a participação dos usuários nas tomadas de decisões do abrigo, em vez de impor regras as quais eles devem simplesmente se sujeitar, poderia contribuir para o fortalecimento da autonomia dos adolescentes.

As ações implementadas pela equipe do abrigo visando ao fortalecimento da autonomia de José constituíram-se, basicamente, da sua preparação para o mercado de trabalho por dois caminhos: a inserção no programa ProJovem Urbano e o aprendizado de ofícios como marceneiro e pintor; e um estágio como ASG na Casa de Passagem II, poucos meses antes do seu desligamento. Contudo, as oficinas profissionalizantes propostas eram sempre por ele abandonadas porque não atendiam a seus anseios particulares de vir a se tornar um jogador de futebol.

Aos 18 anos completos, já no estágio como ASG na Casa de Passagem II, costumava dizer que assim que estivesse empregado iria para o Rio de Janeiro mantendo-se com o dinheiro dos três primeiros salários -, e chegando lá pleitearia uma vaga em uma escola de futebol de algum clube famoso.

Eu quero é juntar dinheiro: três mês só, três mês tá bom. Três mês, eu compro minha passagem e ainda sobra um dinheirinho bom aí que é pra mim comprar comida .... Vou procurar uma porta duma emissora lá; onde ... eu conhecer lá algum apresentador, vou chegar logo de frente; eu vou pedir pra eles arrumarem essa escola de futebol pra mim ir (13 de outubro de 2009).

Não obstante tal demonstração de vontade, durante o período de institucionalização, José nunca 
foi incentivado a pôr em prática tal anseio e a testar suas capacidades, no sentido de ser inserido em atividades esportivas. Acredita-se que o esporte poderia ter representado fator de busca de reintegração social, além de importante rede de apoio fora do abrigo. Por outro lado, ao se ver encaminhado para um trabalho com que não se identificava, sobre o qual não alimentava expectativas, crescia o sentimento de angústia com relação à sua saída definitiva da instituição e mais distante ficava do fortalecimento da sua autonomia.

Atividades como acordar sozinho, andar de ônibus pela cidade, resolver pequenos problemas dentro e fora do abrigo já deveriam ser estimuladas durante o período de institucionalização. No entanto, o que se via era a organização das atividades da maneira mais prática para seus funcionários, com o objetivo de evitar evasões ou problemas com a comunidade; e os adolescentes - muitas vezes em número elevado na Casa - eram mantidos constantemente supervisionados e tutelados.

\section{A maioridade e o desligamento do abrigo}

Ao despertar no dia 11 de outubro de 2008, quando completou 18 anos, José viu transformar-se uma série de elementos que constituíam a sua vida até então, e essa nova realidade causou algumas mudanças no seu comportamento. Ele era conhecido no abrigo por apresentar uma conduta bastante rebelde; estava constantemente envolvido com brigas e destruição do patrimônio da instituição, sendo, por vezes, encaminhado à delegacia de proteção especial - especializada no atendimento de adolescentes. Completos os 18 anos e considerando que agora as consequências poderiam ser mais drásticas, como ser levado à delegacia de plantão, José passou a controlar seu comportamento.

De acordo com a coordenadora da Casa de Passagem III, o fato de José já ter 18 anos e ser o único nessa condição dentre os abrigados passou a refletir na forma como os outros meninos do abrigo se relacionavam com ele, usando desse fato para chantageá-lo. Segundo ela,

Os meninos dizem assim: "Tia, mas engraçado, ele pode falar com a gente de tal jeito e a gente não pode falar com ele; se nós bater nele a gente vai pra delegacia de menor, mas a gente não pode levar ele pra plantão, não?" (13 de outubro de 2009).

A coordenadora também relatou que ele apresentava, constantemente, queixas com relação à sua vida de adolescente no abrigo. Membros da equipe informaram que, no período próximo ao seu desligamento, ele se encontrava arredio e isolado, tendo como única companhia sua namorada. Ela e José se conheceram no abrigo, permanecendo juntos até o dia em que ele foi desligado da instituição. 0 depoimento a seguir, de um dos técnicos da Casa de Passagem III, esclarece um pouco essa questão:

Ele só interage com a namorada dele. Só com a namorada, somente. Tanto que, na hora que os meninos estavam jogando vôlei aqui, uma vez eu estava olhando isso, ele, nesse dia, estava à tarde, e os meninos estavam jogando vôlei e ele estava lá sentado com ela do lado, mas é como se não tivesse mais ninguém em volta deles, somente os dois (21 de outubro de 2009).

No entanto, tendo em vista a maioridade de José e a idade de 15 anos da sua namorada, o relacionamento atinge um novo status, podendo ser considerado como abuso sexual: o namoro passa a ser considerado ilegal e passível de sanção judicial. Assim, o fato de ele se encontrar arredio, isolado, triste e introspectivo no período do desligamento revela o conjunto de desafios a vencer em face da nova situação, assim como o medo e a sensação de abandono que acompanham tais desafios.

Ao discutir a questão do desligamento institucional por maioridade, Martinez e Soares-Silva (2008) denominam essa situação como "desraizamento", por se tratar da saída de um lugar seguro, representado pelo abrigo, para outro ainda não conhecido. Na mesma perspectiva, Castel (2009) afirma que o isolamento é a representação do empobrecimento das relações sociais que, em se tratando de José, se encontravam em um estado de fragilidade, ou mesmo de rompimento. Ainda de acordo com este autor, a ruptura com o vínculo social é uma marca das populações suscetíveis de intervenção social, tanto quanto daquelas marcadas pela pobreza.

Coerente com tal compreensão é o depoimento a seguir, de um dos técnicos da Casa de Passagem com quem se conversou: 
Teve um dia ..., ele chegou do trabalho e ficou sentado ali e estava chorando muito, aí me sentei perto dele e perguntei: "que é que está acontecendo?". Ele não respondeu. "Vamos conversar?". E ele não respondeu, não olhou nem pra mim. Eu me levantei, fui até a sala e perguntei à coordenadora: "você já viu como é que José tá?". Ela disse: "não, como é que ele tá?" ... Ela disse: "deixa ele chorar, o que é que eu posso fazer?". Depois disso, eu comecei a analisar e comecei a perceber, comecei a estudar esse comportamento, que é o quê? Na minha visão é o medo do mundo; de repente ele se deparou com a realidade do mundo, com o que pouca gente comenta com ele, pouca gente conversa com ele sobre a idade dele e ele se deparou com essa realidade: 'estou de maior, vivi a minha vida dentro de um abrigo, hoje eu não tenho mais proteção de nada, tenho que trabalhar, e agora?'. Então, na minha opinião, é como se ele tivesse perguntado 'quem sou eu, o que é que eu vou fazer da minha vida, e agora, o que é que vai ser?'. Então eu percebi isso nesse comportamento dele; como eu venho também percebendo desde que ele começou a trabalhar, esse comportamento dele fechou-se mais ainda. Ele entrou no mundo... Se trancou dentro do mundo dele mais ainda e jogou a chave fora (21 de outubro de 2009).

Com uma rede de apoio social fragilizada, vínculos rompidos e tamanhas incertezas com relação ao futuro próximo, a desinstitucionalização se configurou para José como um momento muito difícil a superar. Da mesma forma que se constatava a necessidade de apoio afetivo e emocional naquele momento em particular, se avaliava como era patente a ausência de orientação para a construção de um projeto de vida durante os anos de institucionalização.

\section{A vida depois do abrigo}

Depois de superado o estágio do 'não saber o que fazer com ele', em dezembro de 2009, aos 19 anos, José foi desligado do abrigo. Para tal concorreu de maneira definitiva pressão do Conselho Tutelar, ou seja, externa à Casa de Passagem III. A alegação do Conselho era de que o jovem não podia mais ficar abrigado porque não poderia mais ser atendido pelo serviço de acolhimento, uma vez que atingira a maioridade, não se enquadrando nas diretrizes de proteção do ECA.
Assim, em novembro de 2009 a equipe do abrigo, com a participação de José, providenciou o aluguel de uma quitinete, com cozinha, quarto e banheiro, situada no bairro de Mãe Luiza, zona leste da cidade, a qual seria mantida pelo município durante três meses. Ficava próximo à casa de uma tia de quem ele dizia gostar muito, ainda que ela nunca o tenha recebido durante sua institucionalização, não sendo possível fortalecer esse vínculo. Alugado o imóvel, em uma semana, José fez sua mudança. A mobília seria comprada aos poucos, com o salário que receberia do emprego que lhe foi oferecido também pelo município.

\section{A inserção no mercado de trabalho}

Como já referido, prestes à sua saída do abrigo José passou a exercer o cargo de auxiliar de serviços gerais no PETI, também vinculado à Secretaria Municipal de Trabalho e Ação Social (SEMTAS), em Natal. 0 trabalho deveria representar conquista fundamental no momento da desvinculação do abrigo, uma vez que criaria possibilidades para o jovem assumir o cuidado da sua vida por conta própria. Contudo, como ele não dispunha das habilidades sociais necessárias para conviver com as formalidades, com a organização, os horários etc. do mundo do trabalho, ou a instituição empregadora assumiria o caráter pedagógico dessa empreitada, ou ele seria demitido em pouco tempo.

Em entrevista, a coordenadora do programa em que José estava empregado relatou algumas dificuldades dele no emprego que, em muito, se referem às rotinas no abrigo, sua profunda carência de conteúdos pedagógicos, educativos, orientadores para a vida em qualquer circunstância:

Chegou aqui, aí o primeiro problema dele é assim... Muito preguiçoso, não fazia nada, a gente tinha que tá mandando. Hoje ele já tem até as iniciativas, mas ainda tá naquele processo, ainda de adaptação, que realmente você tem que orientar: "José, faça isso, José, não faça isso". Era o dia todinho ali no celular, jogando no celular; fui repreender, que naquela hora era pra ele ficar no portão, aí... Essas coisas que ele não teve... Tem um detalhe, né, que a gente diz assim que Casa de Passagem é bom, dá aquele acolhimento, mas acho que desde os 16 anos, já era pra tá dando um empurrãozinho nesse lado, sabe, 
dando obrigações, né, entendeu? Pra ele, porque aí ele chega na idade de 19 anos não sabe nada, nada, nada (29 de janeiro de 2010).

Problemas relacionados ao respeito à autoridade e à hierarquia também foram apontados no depoimento da coordenadora do PETI, que revelou estar muito insatisfeita com o comportamento de José, chegando a ameaçá-lo de demissão já em março de 2010. Informou que a conduta dele vinha sendo inadequada, desrespeitando a ela e aos outros funcionários, não cumprindo regras e horários e se recusando a fazer as tarefas que lhes eram delegadas.

Os funcionários aqui tratam ele bem, mas uma vez por outra ele tira uma brincadeira com as meninas da cozinha. ... Outra coisa também é que você às vezes pede alguma coisa a ele, e ele diz que não vai fazer e fala alto; aí," José, abaixe a voz". A gente pede pra ele ir pegar o lixo da cozinha ou do banheiro, as meninas pedem, é ele que tem que pegar, né?, ele também faz isso, aí você pede, e ele "ah, vai vocês se quiserem". Eu já chamei atenção dele com isso, sabe? Aí, digo: "Tem dois porém, elas não estão mandando em você, elas estão pedindo, e outra que elas são mais velhas, você tem que respeitá-las" (29 de janeiro de 2010).

Ele se recusa a fazer o que a gente manda. Outro dia ele foi até a empresa contratadora do pessoal procurar saber o que um auxiliar de serviços gerais faz, dizendo que mandavam ele recolher lixo e um ASG não tem que fazer isso não! (23 de abril de 2010).

Vale ressaltar que o desrespeito às regras e à autoridade tratava-se de característica que o jovem já revelava durante a institucionalização, muito embora seja provável que nessa oportunidade ele apenas aperfeiçoou o que desenvolvera no contexto familiar. No abrigo, em que o acompanhamento era distante, quando não autoritário, tais comportamentos não traziam consequências mais graves, diferente de quando se deparou com o ambiente do trabalho.

Na primeira entrevista com o adolescente logo após seu desligamento do abrigo, ele relatou estar contente com o emprego e com a nova moradia. Dizia estar feliz, pois agora tinha mais liberdade e podia usar seu poder de compra. Inclusive, afirmou continuar frequentando regularmente o ProJovem e a escola, que era condição da SEMTAS para mantê-lo no emprego. Porém, constatou-se que pelo menos parte do que dissera não era verdade, notadamente quanto às obrigações com o ProJovem Urbano e com a escola, que não mais estava frequentando; isso ressalta seu comportamento dissimulado, imaturo, e oportunista até certo ponto.

\section{Poder de consumo}

Outro elemento que merece atenção, e que se apresentou como problema na desinstitucionalização de José, foi sua relação com o dinheiro e com o consumo. Vividos apenas dois meses no emprego, contraiu mais dívidas no cartão de crédito do que tinha condições de pagar. Logo que recebeu o primeiro salário comprou um aparelho celular de último tipo, roupas, chuteiras, bolas de futebol, dentre outras mercadorias, todas de marcas famosas. Como o que ganhava não era suficiente para cobrir as dívidas, contraiu com o banco um empréstimo de dois mil reais. A coordenadora do PETI, sua empregadora e até certo ponto tutora, ponderou:

Tô no controle aqui, monitorando aqui, mas parece que não tá adiantando não. Com dois cartões de crédito na mão ele já tem um débito, hoje, de dois mil e quinhentos reais. Coisa que eu, ganhando o que eu ganho, não tenho coragem de assumir. A secretária da SEMTAS já disse que colocasse pra ele que a Defesa Civil só paga a ele a casa dele até 30 de março; de março pra lá, ele vai ter que se virar; aí, ele vai pagar 150 de casa e, desse jeito, vai viver como, com trezentos reais? (29 de janeiro de 2010).

Em visita à sua casa no final de fevereiro de 2010, ou seja, transcorridos quatro meses do desligamento, constatou-se que ainda não havia sido comprado nenhum móvel, como geladeira, fogão, mesa, cadeiras. Tinha apenas um colchão, sem lençóis nem travesseiro, que ele ganhara do município, uma caneca plástica e um garrafão de 20 litros de água mineral, com o respectivo suporte, que também lhe fora cedido pela SEMTAS. Contudo, ele adquirira uma televisão de 29 polegadas; e na caixa que lhe servira de embalagem, guardava a caneca usada para beber água.

Do ponto de vista de José, o mau uso do dinheiro refletia imaturidade, despreparo diante dos apelos consumistas da mídia, descompromisso com 
objetos e oportunidades que lhes foram cedidas sem que precisasse se esforçar para conquistá-los. No que concerne à instituição abrigadora, mais uma vez fica patente a falta de concepção pedagógica que contemple a preparação do jovem com vistas a um adulto responsável, pronto para lutar pelo seu futuro de modo íntegro. Acostumado pela proteção quase incondicional que recebera do abrigo durante quatro anos essenciais da sua vida, que supria suas necessidades básicas, agora que tinha dinheiro, fazia todo sentido adquirir os objetos de satisfação do desejo, a que certamente nunca tivera condições de atender com liberdade.

\section{Resgate de referências da vida tutelada}

Entre os catorze e os dezoito anos de idade, período muito importante para qualquer adolescente, José esteve institucionalizado e o abrigo foi o único lugar em que ele poderia encontrar apoio e orientação; a equipe da Casa era sua única referência. Em entrevista realizada em abril de 2010, a coordenadora da Casa de Passagem III revelou que José havia realizado uma visita recente à sua antiga morada, afirmando que apenas queria conversar com ela. Esse retorno, quando se encontrava em dificuldades para administrar a vida livre, pode ser entendido como uma demonstração da necessidade de amparo, orientação e aponta para a importância da continuidade de acompanhamento dos egressos, mesmo após a maioridade e o desligamento do abrigo. A coordenadora da Casa explica:

Ele chegou aqui, falou comigo e foi pra lá, sentou e ficou lá sentado. Não falava nada com ninguém. Ficou um tempão assim. Aí eu pensei 'Meu Deus, ele sente falta daqui, do ambiente! Ele toma isso aqui como uma referência, que nesse caso deveria ser a família que ele não teve, né? Tenho medo, porque agora não podemos fazer mais nada por ele, mas pra mim, na cabeça dele... Sempre que ele precisar, ele acha que pode recorrer à gente (23 de abril de 2010).

De acordo com Siqueira, Zoltowski, Giordani, Otero e Dell'Aglio (2010, p. 13), "na prática, não existe um programa de avaliação e acompanhamento de egressos dos abrigos e, muitas vezes, as instituições de abrigo não possuem equipe ou habilitação técnica para realizar este trabalho". Efetivamente, o que se observa em relação ao abrigamento institucional realizado pelo Estado é que, feito o desligamento, não é mais função da equipe lidar com a orientação do jovem que agora se encontra fora da instituição.

\section{Considerações finais}

O estudo apontou a inexistência de um trabalho em rede voltado para o jovem em situação de acolhimento institucional, bem como inconsistência na sua preparação para a saída compulsória do abrigo. No caso, as ações implementadas assumiram a marca do arranjo, da falta de planejamento, de sistemática, assim como do paternalismo e do assistencialismo. A garantia de direitos foi confundida com a oferta de favores, reeditando a política de assistência social observada no início do século XX.

Ademais, ressalte-se a completa ausência de trabalho no âmbito da família e da comunidade do adolescente em situação de vulnerabilidade social, antes mesmo de ele ser institucionalizado. No caso estudado, a falta de apoio da família e as ameaças oriundas de membros da comunidade de origem apontavam a institucionalização e o consequente afastamento do convívio familiar e comunitário como única opção com vistas à salvaguarda de direitos; no entanto, ficou evidente que essa situação causou prejuízo para o jovem, em termos de desenvolvimento, saúde, bem-estar e qualidade de vida.

Ressente-se da falta de políticas públicas que, articuladas com os abrigos, garantam os direitos dos jovens que vivenciam experiências de desinstitucionalização. 0 jovem que não pode mais ser amparado por um serviço de atendimento especializado e que ainda se encontra em situação de vulnerabilidade deve encontrar em políticas específicas a salvaguarda dos seus direitos como cidadão e, por conseguinte, a continuidade do apoio às suas necessidades. Mais que visar à correção e adequação dos sujeitos às suas regras, os serviços devem objetivar a produção de sua autonomia e continuamente atuar preservando o direito à esperança, fundamental para o exercício pleno da cidadania. 


\section{Referências}

Castel, R. (2009). Da indigência à exclusão, a desfiliação: Precariedade do trabalho e vulnerabilidade relacional. In A. Lancetti \& G. Baremblitt (Org.). Saúde e loucura. (pp. 21-48). São Paulo: Hucitec.

Conselho Nacional dos Direitos da Criança e do Adolescente [Conanda] \& Conselho Nacional de Assistência Social [CNAS], (2008). Orientações técnicas para serviços de acolhimento institucional para crianças e adolescentes. Brasília: Conanda/ CNAS.

Constantino, E. (2000). Meninos institucionalizados: A construção de um caminho. São Paulo: Arte \& Ciência.

Figueiredo, C. I., Sader, E. S., \& Caldeira, T. (1987). Fogo no pavilhão - Uma proposta de liberdade para o menor. São Paulo: Brasiliense.

Goffman, E. (1961). Manicômios, prisões e conventos. São Paulo: Perspectiva.

Instituto de Pesquisa Econômica Aplicada, [Ipea], \& Conselho Nacional dos Direitos da Criança e do Adolescente, [Conanda], (2004). $O$ direito à convivência familiar e comunitária: Os abrigos para crianças e adolescentes no Brasil. Recuperado em 10 janeiro, 2013, de http://www.ipea.gov.br/sites/000/2/publicacoes/bpsociais/bps_11/ENSAIO3_Enid.pdf.
Janczura, R. (2005). Abrigos para adolescentes: Lugar social de proteção e construção de sujeitos? Revista Virtual Textos \& Contextos, 4, 1-19.

Lancetti, A. A casa de inverno: Notas para desinstitucionalização da assistência social. In A. Lancetti \& G. Baremblitt (Org.). Saúde e loucura: Grupos e coletivos. (pp. 71-84). São Paulo: Hucitec.

Martinez, A., \& Soares-Silva, A. (2008). O momento da saída do abrigo em função da maioridade: A voz dos adolescentes. Psicologia em Revista, 14(2), 113-132.

Siqueira, A., \& Dell'Aglio, D. (2006). O impacto da institucionalização na infância e na adolescência: Uma revisão de literatura. Psicologia \& Sociedade, 18(1), 71-80. doi:10.1590/S0102-71822006000100010.

Siqueira, A., Zoltwski, A., Giordani, J., Otero, T., \& Dell'Aglio, D. (2010). Processo de reinserção familiar: Estudo de casos de adolescentes que viveram em instituição de abrigo. Estudos de Psicologia, 15(1), 7-15. doi:10.1590/S1413-294X2010000100002.

Soares, J., \& Camargo Junior, K. (2002). A autonomia do paciente no processo terapêutico como valor para a saúde. Interface: Comunicação, Saúde, Educação, 11(21), 65-78. doi:10.1590/S1414-32832007000100007. 